\title{
Leg ischemia post-varicocelectomy
}

This article was published in the following Dove Press journal:

International Medical Case Reports Journal

8 March 2016

Number of times this article has been viewed

\author{
Abdullah M Al-Wahbi \\ Shaza Elmoukaied ${ }^{2}$ \\ 'Division of Vascular Surgery, \\ Department of Surgery, King \\ Abdulaziz Medical City, Riyadh, \\ Saudi Arabia; ${ }^{2}$ Department of Surgery, \\ Dr Sulaiman Al Habib Hospital, \\ Riyadh, Saudi Arabia
}

\begin{abstract}
Varicocelectomy is the most commonly performed operation for the treatment of male infertility. Many surgical approaches are used as each of them has advantages over the other and is preferred by surgeons. Vascular injury has never been reported as a complication of varicocelectomy apart from testicular artery injury. We present a 36-year-old male who developed leg ischemia post-varicocelectomy due to common femoral artery injury. He was successfully treated by using a vein graft.
\end{abstract}

Keywords: varicocele, varicocelectomy, complications, vascular injuries

\section{Introduction}

Varicocele is a collection of abnormally dilated, tortuous spermatic veins. ${ }^{1,2}$ The prevalence of varicocele is reported to be as high as $10 \%-15 \%$ in the general population, 30\%-35\% in men with primary infertility, and 69\%-81\% in men with secondary infertility. The varicocele has clinical importance because it is the most common cause of male infertility and is correctable. ${ }^{1,3-5}$ The causes of varicocele are multifactorial, but in the end, the result is a pathological dilatation of the veins draining the testicles. ${ }^{6}$ Varicocelectomy is by far the most commonly performed operation for the treatment of male infertility. ${ }^{7,8} \mathrm{~A}$ variety of surgical and nonsurgical approaches have been advocated for varicocelectomy. They include minimally invasive procedures, such as laparoscopic varicocelectomy and transvenous percutaneous embolization, and the traditional open surgical approach (retroperitoneal, inguinal, and subinguinal). ${ }^{1,5,7}$ Limb ischemia occurs because of a decrease in the blood flow to a limb, resulting in a potential threat to the viability of the extremity. Unfortunately, not only is there a threat to the limb, but these patients are also at high risk for death. Leg pain, coldness, and paresthesia are the most common symptoms. Causes of limb ischemia could be embolus, thrombosis, or trauma (iatrogenic, blunt, and penetrating). Most common iatrogenic trauma are from vascular or cardiac diagnostic and interventional procedures. Leg ischemia as a complication of varicocelectomy has never been reported.

\section{Case report}

A 36-year-old Hispanic male presented to the vascular clinic on February 4, 2015, with a history of progressive left lower extremity pain with walking for 1 month. The patient noted a marked decrease in his walking distance over 1 month before his evaluation. At presentation, he was able to ambulate 50-75 feet only before the onset of left calf pain. On January 8, 2015, the patient underwent bilateral varicocelectomy for bilateral 
varicoceles associated with primary infertility. He admitted to having complications postoperatively, consisting of a large left groin hematoma and left leg pain. The hematoma was treated conservatively with observation and antibiotics. The left groin hematoma resolved 1 week postoperatively, but the left leg pain was increasing, especially with ambulation. He was assured by the operating surgeon that his surgery was successful and that the leg pain was temporary. However, the patient presented to our vascular surgery clinic, seeking a second opinion. His past medical history was unremarkable. He denied any history of tobacco use, hypercholesterolemia, hypertension, diabetes mellitus, or lower extremity trauma. He was without any systemic complaints. At the time of presentation, the patient denied taking any medication. The physical examination was remarkable for normal upper extremity pulses and blood pressures. The lower extremity examination was remarkable for bilateral groin scars, no swelling or hematoma, absent left femoral and pedal pulses, and normal right femoral and pedal pulses. There were no motor or sensory deficits. Ankle-brachial indices were 0.5 on the left and 1.0 on the right. Cardiac and other investigations were normal, although these do not exclude arterial emboli

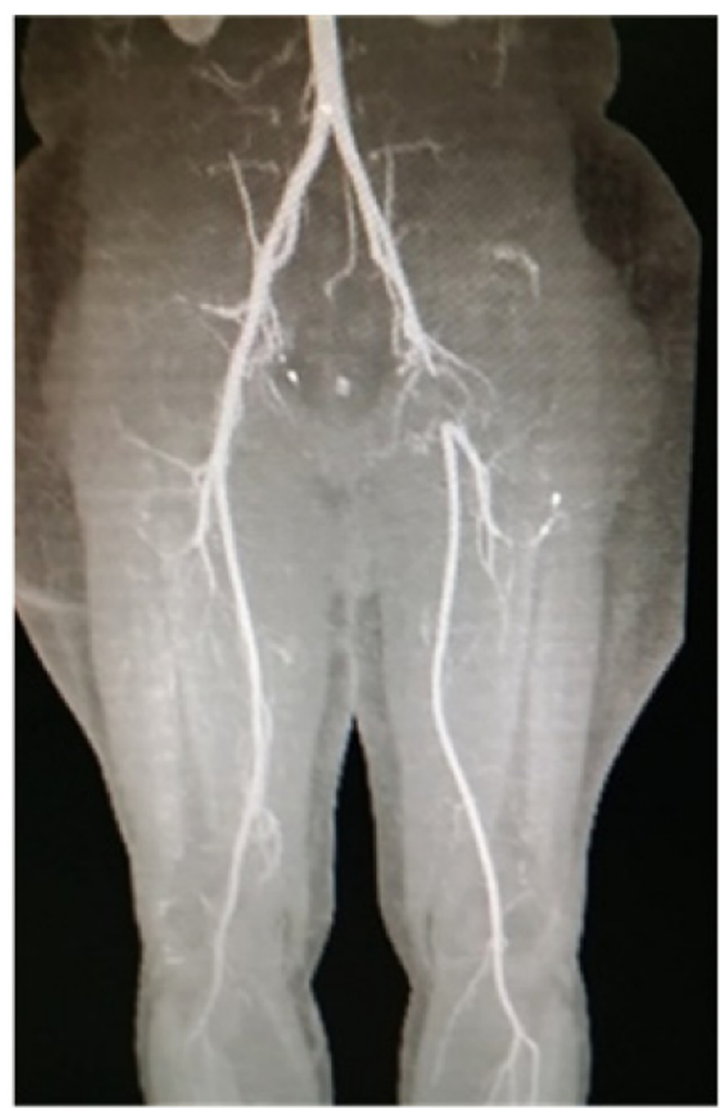

Figure I CT angiogram showing complete occlusion of left common femoral artery. Abbreviation: CT, computer tomographic.

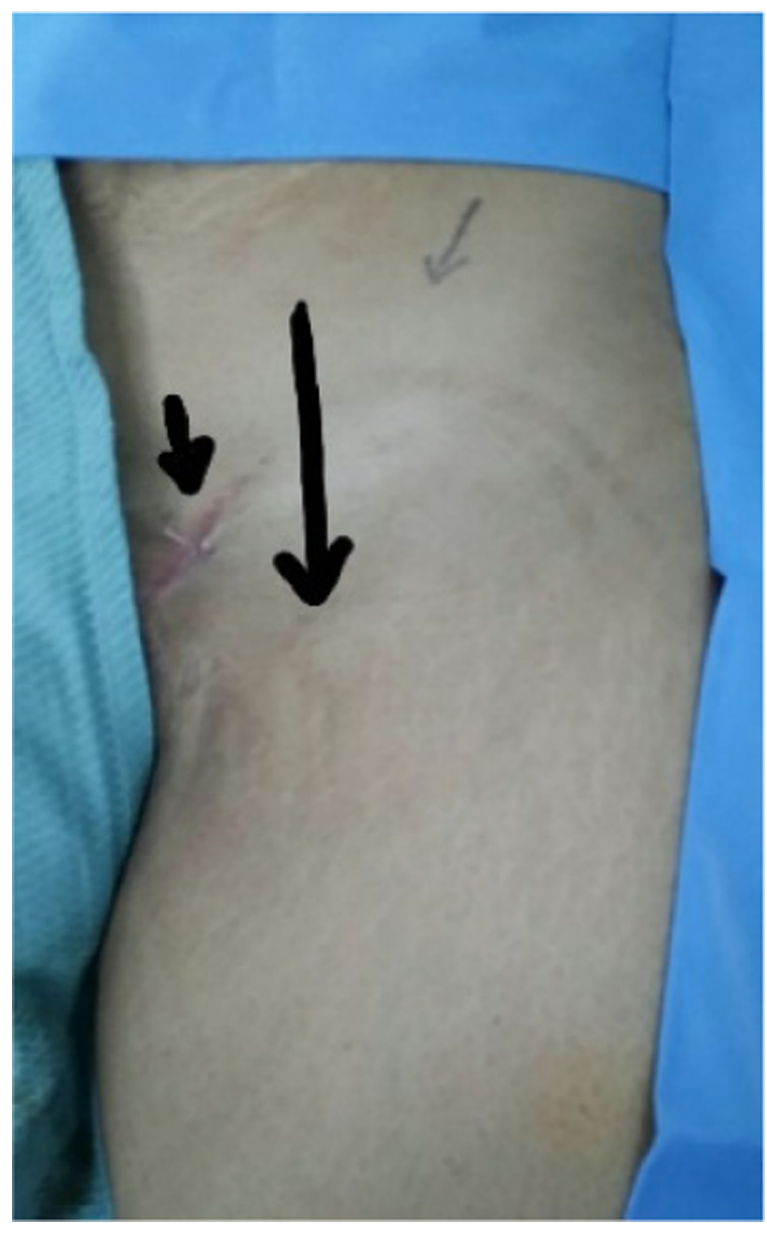

Figure 2 Left groin area showing scar of varicocelectomy (short arrow) and the course of left common femoral artery (long arrow).

completely. Computerized tomographic (CT) angiogram was requested, and the patient was asked to bring a copy of his previous surgery report. CT angiogram showed complete occlusion of the left common femoral artery up to its bifurcation with normal runoff (Figure 1). The varicocelectomy



Figure 3 Left groin exposure with the left common femoral artery (white arrow) and its bifurcation (yellow arrow) controlled with vessel loops and complete loss of arterial structure in between (green arrow). 


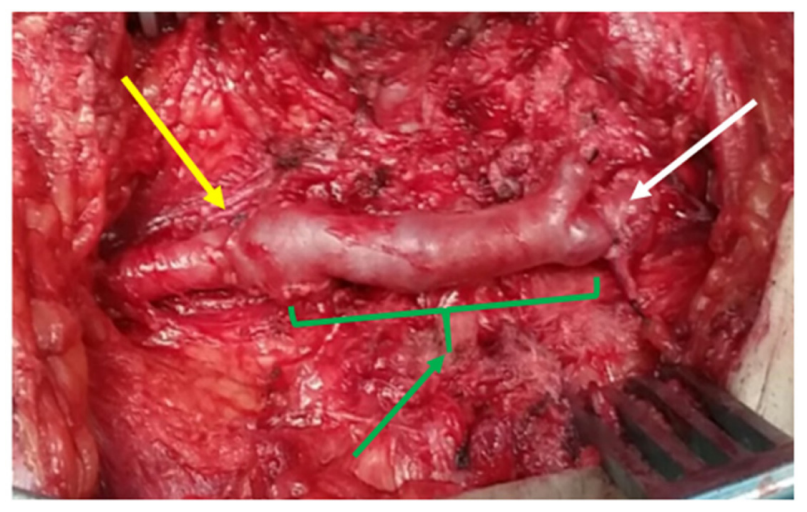

Figure 4 Left saphenous vein interposition graft (green arrow) anastomosed to the left common femoral artery (white arrow) and its bifurcation (yellow arrow).

surgical report denied any vascular complications apart from minor intraoperative bleeding from the left side controlled by stitches. The patient was informed about the CT angiogram finding and that he needed revascularization of his left leg with the possibility of using a vein graft. On February 7, 2015, through a left groin longitudinal incision, the left common femoral artery was controlled with vessel loops (Figure 2). Upon dissection, the femoral artery was observed to be completely destroyed, with no anatomical configuration except for fragments of the wall (Figure 3). At the bifurcation, the profunda and superficial femoral artery were normal with a thrombus at the stump. The incision was extended along the great saphenous vein, which was harvested. A reversed interposition saphenous graft between the left common femoral artery and its bifurcation was performed (Figure 4). Postoperatively, the patient had palpable pedal pulses. He was discharged on the third postoperative day. In outpatient follow-up, the patient was doing well and ambulating normally. At 6-month follow-up, he had palpable pedal pulses bilaterally and no complaints. The patient provided a written informed consent and the ethical approval was obtained from the Ethical Committee of Dr Sulaiman Al Habib Hospital, Riyadh, Saudi Arabia.

\section{Discussion}

From the skin surgical incisions and the surgeon's brief operative report, we believe that the inguinal approach was used for varicocelectomy in our patient. In this approach, the position of the superficial inguinal ring is marked on the skin, approximately $3-5 \mathrm{~cm}$ over the inguinal canal. The incision is extended around $2 \mathrm{~cm}$ from the mark, following the natural lines of the skin. The spermatic cord is elevated, and any external spermatic veins that are running parallel to the spermatic cord or perforating the floor of the inguinal canal are identified and ligated. Both layers of spermatic fascia are incised longitudinally, and all arteries, including the testicular artery, are preserved. All remaining inner spermatic veins, with the exception of the vas deferens vein, are clipped or ligated..$^{8-13}$

Hydrocele is the most common complication of varicocelectomy. Recurrent varicocele, wound infection, testicular atrophy, and infertility are rare but significant complications. Hematomas (scrotal or wound) are less than $1 \%$ after varicocelectomy. ${ }^{14-16}$ In a literature review, over 5,000 patients pooled from 33 studies of varicocelectomy were evaluated. There were no vascular complications, and scrotal hematoma was very rare. ${ }^{6}$

A young patient with no vascular risk factors or trauma presenting with symptoms of leg ischemia demands a high index of suspicion for a list of rare causes of leg ischemia like popliteal entrapment, Buerger's disease, embolisms, etc. In our patient, we had a high suspicion of surgical complication

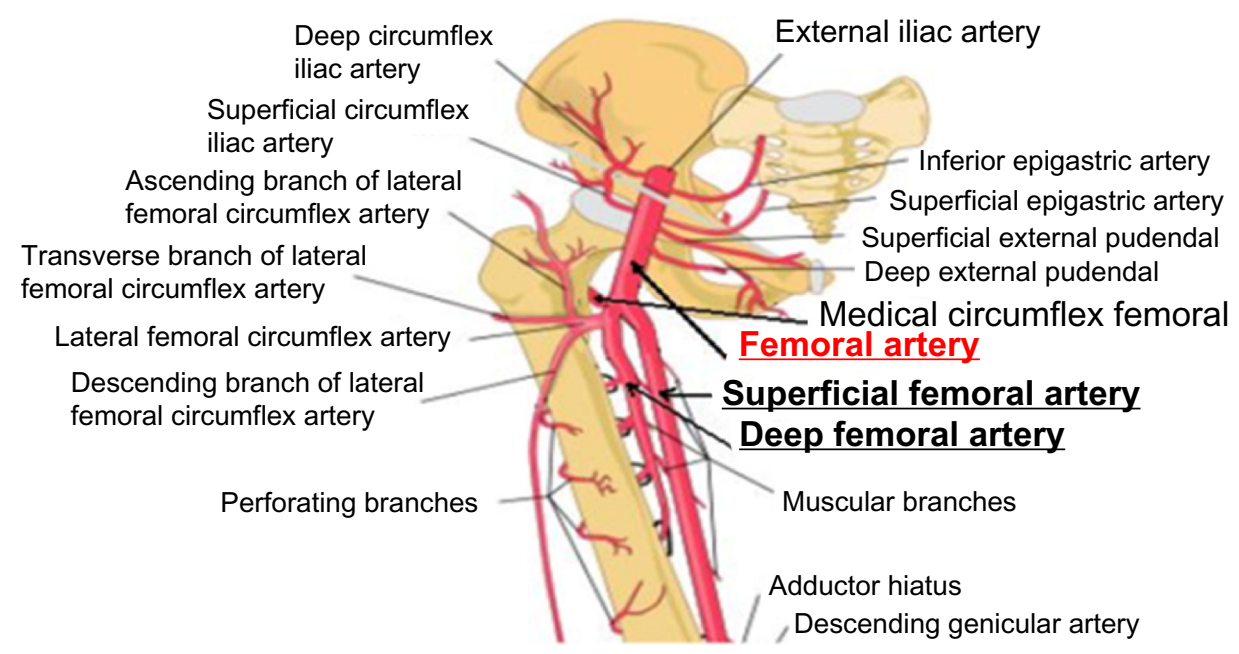

Figure 5 Common femoral artery and its branches around the inguinal canal. 
causing damage to the femoral artery. However, the surgeon report and the known complications of varicocelectomy made us question our preliminary diagnosis. Cardiac and other investigations were normal, although these do not exclude arterial emboli completely.

We hypothesized that during varicocelectomy through the inguinal approach, the surgeon had encountered a bleeding from the left groin (most likely from branches of the common femoral artery adjacent to the surgical field, epigastric, or pudendal arteries) (Figure 5). In these circumstances, an appropriate bleeding control is crucial. If the surgeon cannot identify the bleeding source, he should not apply blind sutures as that will cause further vascular and even nerve damage. The surgeon should apply pressure and ask the vascular surgeon for support. Our patient had his varicocelectomy in a private hospital where all surgical specialties including vascular surgery are available. Instead, the surgeon tried to control the bleeding by multiple blind sutures. He managed to traumatize the femoral artery, which eventually led to its thrombosis and destruction.

A thorough literature search using PubMed (a search engine of the United States National Library of Medicine and the National Institutes of Health), MEDLINE database, and individual urology journals failed to find a similar report. To our knowledge, our case is the first to report leg ischemia (vascular injury) as a complication of varicocelectomy.

\section{Conclusion}

During the inguinal approach for varicocelectomy, dissection deeper than the inguinal ligament should be avoided. When bleeding is encountered, blind sutures should never be used. Direct pressure is applied, followed by careful dissection to locate and control the bleeding source. Asking for a vascular surgeon's support is recommended.

We have presented the case of a 34-year-old male with left leg ischemia that resulted from a varicocelectomy procedure. No similar case in the literature has been reported.

\section{Disclosure}

The authors report no conflicts of interest in this work.

\section{References}

1. Choi WS, Kim SW. Current issues in varicocele management: a review. World J Mens Health. 2013;31:12-20.

2. Baazeem A, Belzile E, Ciampi A, et al. Varicocele and male factor infertility treatment: a new meta-analysis and review of the role of varicocele repair. Eur Urol. 2011;60:796-808.

3. Sabanegh E, Agarwal A. Male infertility. In: Wein AJ, Kavoussi LR, Novick AC, Partin AW, Peters CA, editors. Campbell-Walsh Urology. 10th ed. Philadelphia, PA: Saunders; 2012:636-637.

4. Gorelick JI, Goldstein M. Loss of fertility in men with varicocele. Fertil Steril. 1993;59:613-616.

5. Kupis $Ł$, Dobroński PA, Radziszewski P. Varicocele as a source of male infertility - current treatment techniques. Cent European J Urol. $2015 ; 68: 365-370$

6. Diegidio P, Jhaveri JK, Ghannam S, Pinkhasov R, Shabsigh R, Fishc H. Review of current varicocelectomy techniques and their outcomes. BJU Int. 2011;108:1157-1172.

7. Binsaleh S, Lo KC. Varicocelectomy: microsurgical inguinal varicocelectomy is the treatment of choice. Can Urol Assoc J. 2007;1:277-278.

8. Pajovic B, Radojevic N, Dimitrovski A, Radovic M, Rolovic R, Vukovic M. Advantages of microsurgical varicocelectomy over conventional techniques. Eur Rev Med Pharmacol Sci. 2015;19:532-538.

9. Goldstein M, Gilbert BR, Dicker AP, Dwosh J, Gnecco C. Microsurgical inguinal varicocelectomy with delivery of the testis: an artery and lymphatic sparing technique. J Urol. 1992;148:1808-1811.

10. Sun HB, Liu Y, Yan MB, Li ZD, Gui XG. Comparing three different surgical techniques used in adult bilateral varicocele. Asian J Endosc Surg. 2012;5:12-16.

11. Jungwirth A, Diemer T, Dohle G, et al. Guidelines on male infertility. Eur Urol. 2012;61:150-163.

12. Palomo A. Radical cure of varicocele by a new technique: preliminary report. J Urol. 1949;61:604-607.

13. Ghanem H, Anis T, Al-Nashar A, Shamloul R. Subsurgical microvaricocelectomy versus retroperitoneal varicocelectomy comparative study of complications and surgical outcome. Urology. 2004;64:1005-1009.

14. Ross LS, Ruppmen N. Varicocele vein ligation in 565 patients under local anesthesia: a long-term review of technique, results and complications in light of proposed management by laparoscopy. J Urol. 1993;149:1361-1363.

15. Jarow JP, Assimos DG, Pallaway DE. Effectiveness of laparoscopic varicocelectomy. Urology. 1993;42:544-547.

16. Enquist E, Stein BS, Sigman M. Laparoscopic versus subinguinal varicocelectomy: a competitive study. Fertil Steril. 1994;61:1092-1096.
International Medical Case Reports Journal

\section{Publish your work in this journal}

The International Medical Case Reports Journal is an international, peer-reviewed open-access journal publishing original case reports from all medical specialties. Previously unpublished medical posters are also accepted relating to any area of clinical or preclinical science. Submissions should not normally exceed 2,000 words or

\section{Dovepress}

4 published pages including figures, diagrams and references. The manuscript management system is completely online and includes a very quick and fair peer-review system, which is all easy to use. Visit $\mathrm{http}: / / \mathrm{www}$.dovepress.com/testimonials.php to read real quotes from published authors. 